\title{
Behaviour Modification: An Efficacious Tool of Shaping Individual Behaviour Productive and Supportive to Organizational Goal Attainment
}

\author{
Surendra Bahadur Bharijoo
}

\begin{abstract}
This article intends to shed light on the basic concept of Behaviour Modification which is drawing attention increasingly of managers and practioners in shaping behavior of people with whom they are dealing constantly in the organization. Researches and studies revealed that Behaviour Modification can be an efficacious tool in modeling individual behaviours if it is appropriately used with caution. As such, it is also attempted to present here the basic steps and guidelines for its application. In addition to these, the article attempts to point out experiences and limitations of application of Behavioural Modification as explained by its researchers.
\end{abstract}

Key words : Behaviour, modification, individual, organization, goal attainment.

An organization is set up to achieve a destined goal (s). Money, materials, machines methods and manpower (human resources) are assembled mobilized and utilized to perform jobs for attaining organizational goal(s). It is human resources who perform works (jobs) and mobilize various other resources efficiently and effectively. Human Behaviour at works has a profound impact in the persuit of achieving organizational goal. If human behaviour at works are not productive and supportive, the attainment of organizational goal will suffer. Super visor and manager of all roles and ranks required to be interested in the study of how people behave at works. Such study must enable them to understand, predict and modify human behaviour of their subordinates. Hence, supervisor and managers must devote their time and efforts in understanding individual and group job behaviour. Note it well that only understanding is not enough. On the basis of the accumulated knowledges gained so far, they should be capable of predicting job behaviour of their subordinates. How each of them is likely to behave at his/her job? Such prediction is to be made while dealing with them. More importantly, a supervisor/manager is required to modify individual behaviour (make job behaviour productive and supportive) by applying the knowledges, understandings, prediction and skills about human behaviour. Molding human behaviour is not an easy task. It is both interesting and challenging job of all level managers/supervisors. Shaping/Modify/Molding behaviour is technically called as behavioural modification in the language of organizational behaviour. It has been emerging as an efficacious tool of organizational behaviour. Behaviour 
Modification is a deliberate effort to mold individual behaviour by guiding his/her learning in graduated steps. It is concerned with systematically reinforcing each successive step that moves the individual closure to the desired response. It is a label used to refer to techniques designed to change employee behaviour on the job using reinforcement theory.

Behaviour modification is rooted on the idea that behaviour depends on its consequences. So it is concerned with making employee behaviour productive and suppertive by manipulating their consequences. In other words, it is shaping individual behaviour into new patterns that most benefit the organization as well as individual.

\section{Law of Effect}

The concept of Behaviour Modification evolved from the experimental work of B.F. Skinner. It relies heavily on the law of effect which states that an individual tends to repeat behaviour that is followed by favourable consequences (reinforcement) and tends not to repeat behaviour that is followed by unfavourable consequences. Assume for example that an employee found that helping a trainee learned the job produced desirable consequence. The helping behaviour would tend to be repeated with the next trainee. But if a helping effort produced only conflict and problems, then the employee would tend not to help the next trainee.

\section{Reinforcement}

The term 'Reinforcement' here means that it is anything the individual finds rewarding. It is related to the psychological process of motivation and is environmentally based. Reinforcers are external environmental events that follow a response. In general terms motivation is an internal explanation of behaviour where as reinforcement is an external explanation of behaviour. Hence reinforcement can be defined as anything that increases the strength of response and tends to induce repetitions of the behaviour that preceded the reinforcement. Something reinforcing means it strengthens the response preceding it and induces repetitions of the response. Reinforcement may be positive and negative. But both reinforcements strengthen the response and increase the probability of repetition.

\section{Major Two conditions for Application}

Two basic conditions are required for effective application of behaviour modification. Firstly, the supervisor/manager must be able to identify some powerful consequences as perceived by the employee and secondly, the supervisor/manager then must be able to administer them in such a way that the employee will see the connection between the behaviour to be affected and the consequences. 
The law of effect emerges from learning theory which suggests that we learn best under pleasant environment. As the concept of behaviour modification states that external consequences tend to determine behaviour, it is also related to the law of effect. The benefit of the concept is that it places a greater responsibility on the shoulder of the supervisor/ manager.

\section{Alternative consequences (Reinforcement)}

Many organizations have been using various forms of behaviour modification which emphasizes more on the use of rewards and other alternative consequences to sustain job behaviour. Before using it, the supervisors/managers must decide whether they wish to increase the probability of an individual's continued behaviour or decrease it. Once it is decided, then $\mathrm{S} /$ he has two choices to make which determines the type of consequences to be applied.

First, should s/he use a positive or a negative consequence?

Second, should s/he apply it or withhold it?

The answers to these questions result in four ways. It means there are basically four ways in which to shape/mold employee behaviour on the job. Those four ways are unique alternative consequences as discussed below.

\section{Positive Reinforcement}

Behaviour is primarily encouraged by positive reinforcement. When a response is followed by something pleasant, it is called positive reinforcement. Positive reinforcement provides a favourable consequence that encourages repetition of a behaviour. An employee for example, may find that when high quality work is done, the supervisor gives a reward of recognition since $\mathrm{s} /$ he likes recognition as a pleasant consequence, behaviour is reinforced and the employee tends to want to do high quality work again. The reinforcement always should be contingent on the employee correct behaviour.

To improve job performance, the management must apply a program of positive reinforcements. The regular feedback and recognition give employees consequences that strongly influence their job behaviour. Positive reinforcement strengthens and increases behaviour by the presentation of a desirable consequences. It is an effective shaping tool of behaviour. It is so behaviour modification is considered to be a systematic and progressive application of positive reinforcements. It occur, when more frequent or more powerful reinforcements are successively given as one comes closure to the desired behaviour. Even though the completely correct behaviour does not yet occur it is encouraged by giving positive reinforcement for behaviour in the desired direction. Shaping is especially useful for teaching 
a complex tasks. An example of a shaping is the training procedure used by a supervisor of a small sized retail store which can not afford for a centralized training program for its new sales clerks. The supervisor is responsible for sales training to such new sales clerks who do not know in the beginning how to deal with customers effectively. The supervisor then explained the proper sales procedures. S/he observed the clerk's behaviour from time to time. When the clerk showed improved behaviour, s/he expressed approval and encouraged the employee. Since it was favourable and pleasant recognition for the employee, it helped to shape behaviour in the correct direction.

\section{Negative Reinforcment}

When a response is followed by the termination or withdrawal of something unpleasant, it is called negative reinforcement. It is the removal of something undesirable in the situation. Negative reinforcement occurs when behaviour is accompanied by removable of an unfavourable consequence. It is not same as punishment which normally adds something unfavourable/ unpleasant in the situation. Negative reinforcement strengthens and increases behaviour by the termination or withdrawal of an undesirable consequence. As the law of effect professed, behaviour responsible for the removal of something unfavourable state is again encouraged. An example of negative reinforcement is the experience of a jet aircraft mechanic who learned that if s/he wore noise suppressors over his/her ears, $\mathrm{s} /$ he could prevent discomfort from the jet engine noise. This reinforcement encouraged her/him to wear the proper noise equipment.

\section{Punishment}

Punishment is the administration of an unfavourable consequence that discourages a certain behaviour to reoccur again. It is causing an unpleasant condition in an attempt to eliminate an undesirable behaviour. Punishment is anything which weakens behaviour and to decrease its subsequent frequency. It is also a withdrawal of a desirable consequence in the individual's situation before the undesirable behaviour occurs. Although punishment may be necessary sometimes to discourage undesirable/negative behaviour, it should be used with caution because it has certain limitations. For example- Giving an employee a two day suspension from work without pay for showing up alcohol drink. Punishment primarily discourages an undesirable behaviour but it does not directly encourage any kind of desirable behaviour. So it is not a very satisfactory practice to apply punishment. However it may serve as a social cue to others of the value of acceptable behaviour. Another problem is that punishers may be disliked for their disciplinary actions which may place a barrier on the work relationships and reduce the punisher's effectiveness when offering future 
reinforcements. Also individual who is punished may be unclear about what specific part of his/her behaviour is being punished. And it is possible that some desirable behaviour may be accidentally discouraged.

\section{Extinction}

Extinction is the withdrawal of a desirable/pleasant consequence that is contingent upon the individual's behaviour. In other words, it is the withholding of significant positive consequences that were previously provided for a desirable behaviour. Such desirable learned behaviour needs to be reinforced to encourage the individual to repeat the action again and again in future. If no such reinforcement is given by the supervisor/manager, the desirable (productive and supportive) behaviour of the employee tends to diminish through lack of reinforcement. The withdrawal of desirable consequence under extinction occurs after the behaviour is emitted. An example: an employee had been praised once for his/her creative suggestion. S/he again made three suggestions to his/her supervisor but over a period of several weeks, the supervisor did neither reject nor accept them or do anything else. The suggestions so made disappeared. As an effect the employee's suggestion making behaviour was extinguished by the lack of consequences. In these case, the supervisor did not intend to cause the extinction but it has been used as conscious strategy. It can be concluded that the supervisor can gain the benefits of extinction by simply ignoring undesirable employee behavior. Another example is the transferring a very talkative computer typist from presentused-to-department to another department which is inconvenient and far away from his/her residence- is an example of extinction strategy for the typist's talkative behaviour.

There are many other sources of need satisfaction inside and outside the work place which are beyond the supervisor's control. Managers can achieve more favourable results by actively manipulating the favourable or unfavourable consequences of behaviour. An illustration of four types of consequences is given below.

\begin{tabular}{|c|c|c|}
\hline Application & Punishment & Positive Reinforcement \\
\hline $\begin{array}{r}\text { Supervision/Manager's use } \\
\text { Withdrawal }\end{array}$ & Negative Reinforcement & Extinction \\
\hline
\end{tabular}

\section{The Steps of Behaviour Modification}

If behaviour modification technique is to work effectively in getting shaped of employee behaviour, it must be well designed and systematically applied. The following steps may aid in this regard. 


\section{Identify the Critical Behaviour}

The critical Behaviour of employees that have significant impact on performance must be identified Employees are engaged in several behaviour in the organization. Out of these, some behaviour may be critical such as alcohol drinking habit at work place, absenteeism, tardiness and or not doing the assigned task properly. If such behaviours of employees are modified, good results could be expected afterwards. It is, therefore, necessary to identify exactly which behaviours are the critical determinants of success on any given job.

Critical behaviour may be identified through two approaches. One approach is to discuss with the individual (s) closest to the job such as the actual job holder, immediate supervisor, the subordinates and sometimes coworkers. Obviously assumed that the individual (s) who knows the job can most accurately identify the critical job behaviour. Another approach to identify the critical behaviour is to conduct a systematic job behaviour audit. Such audit would systematically analyze each job in question in such a way that the given job is analyzed by using job analysis techniques commonly applied in human resource management. The job holder, the immediate supervisor, and other closest individuals to the job are involved in such behaviour audit.

\section{Guidelines For Identifying Critical Behaviour.}

\section{a. Direct Performance Behaviour}

Only direct performance behaviours should be considered. An employee's bad attitude and someone's goofing off (behave stupidly or irresponsibly) are not accepted for this purpose. Direct performance behaviours such as absenteeism, tardiness or promptness complaints or constructive comments and doing or not doing a particular task or procedure that does have impact on to quantity and/or quality outcomes may be appropriate critical behaviour for behaviour modification. Two criterion in this regard should considered . (a) The critical behaviour should be operationally measurable and (b) such direct performance behaviour should have direct impact on a performance outcome.

\section{b. Performance Deficiency}

Another helpful guidelines for identifying critical behaviour is to work backward from an obvious performance deficiency. Just as not all behaviours contribute to performance for example, complaining behaviour may have nothing to do with performance. So also, all performance problems may not relate to behaviours. For example, the actual cause of a poor performance of a task in a manufacturing organization may be due to fault machinery 
or poorly trained workers who do not know the proper procedures or unrealistically high production standard. These causes are not directly related to behaviour problem but performance problems which also must be solved for seeking overall performance improvements of the organization.

\section{Measurement of the behaviour}

Once critical behaviours are identified, they should be measured operationally. On the basis of observation or counting by extracting from existing records frequency, the number of times that identified critical behaviour is occurring under present condition should be measured well. Sometimes, it is discovered that the certain critical behaviour identified is occurring much less or much more frequently than anticipated. Such baseline measure helps to indicate whether the problem is much more smaller or much more bigger than was thought to be the case. If it is within the acceptable limit, no action may be required. If it is more, it must be changed. Measurement helps to drop the problem because there is no need of changing it atleast in prevailing condition. For example- Attendance of an individual may be identified as a critical behaviour which needs to be changed as reported by the supervisor. But counting of the records revealed that s/he is having 96 percent attendance which may be acceptable range.

The purpose of baseline measurement is to provide objective frequency data. on the critical behaviour. Busy managers may feel that they do not have time to check or record behaviour frequencies objectively. But they need to do in order to use the behaviour modification approach effectively.

\section{Functional Analysis}

After having identified and measured critical behaviours hindering to successful job performance, it is then necessary to determine what are the causes and consequences of these behaviours. It is called as functional analysis. Which involves a detailed examination of critical behaviours of the employees to determine its consequences and conditions leading to their occurances. In other words, $\mathrm{ABC}$ analysis as a tool is applied to help functional analysis of the critical behaviour. It identifies antecedent cues (A) things or circumstance that comes before another and contingent consequences (c) of the performance behaviour (B). For example- the following table presents $\mathrm{ABC}$ functional analysis of absenteeism behaviour. 
A

Antecedent Cues

Illness/ accident

Hang over

Lack of transport

Family problems
B

Behaviours

Getting up late

Sleeping in

Staying home

Working at home
C

Consequences

Discipline programs

Verbal reprimands

Written reprimands

Dismissals

The functional analysis step of behaviour modification brings out the problem solving nature of the technique. It pinpoints the most significant practical problem of using an O.B.Mod. approach to change critical performance behaviours. Only the contingent consequences have an impact on subsequent behaviour. The functional analysis must make sure that the contingent consequences are identified and the analyst must not be deluded by the consequences that on the surface appear to be affecting the critical behaviour.

\section{Evaluation of Performance Improvement}

The final step in behaviour modification is the systematic evaluation whether: the intervention strategies are working properly or not. The basic purpose of behaviour modification is to bring change in undesirable behaviours so as to improve performance. The evaluation must be made on this line. Changed behaviours can be compared with baseline behaviours and deviation can be noted. If there is positive change, it suggests that the strategies are successful. If the change is not significant, it may call for adoption of more appropriate strategies.

In this final step of behaviour modification, the need for four levels of evaluation reaction, learning, behavioural change and performance improvement is emphasized.

In the reaction level, attempt is to be made to assess whether or not the supervisor using the intervention strategy and the individual on whom the reinforcement is applied, both like it. If O.B. Mod. is well received, the reaction is likely to be positive and there exists a better chance of its being applied effectively. Reaction evaluations are helpful because of the following reasons.

1. Positive reactions help ensure organizational support.

2. They can provide information for planning future programmes.

3. Favourable reactions can enhance the other level of evaluations learning behavioural change and performance improvements.

4. They can provide useful comparative data between units and across time.

Learning is the second level of evaluation. It is important when first implementing an O.B. Mod. Approach. Do the people using the approach understand theoretical backgrounds. underlying assumptions, the meaning of and reasons for and the steps in the model? If they 
do not, the model will again tend to be used ineffectively?

The third level of evaluation is behavioural change. Are behaviours actually being changed? The charting of behaviours gives objective data for this level of evaluation.

Performance Improvements is the final level of evaluation. It is the most important concern. The basic objective of O.B. Mod. is not just to receive a favourable reaction, learn the concept and change behaviours. These are to contribute on improvement of performance. Hard measures such data on quantity and quality, turnover, absenteeism, customer complaints, employee grievances, length of patient stay, number of clients served and rate of return on investment and scientific methodology are used, whenever possible to evaluate systematically the impact of O.B. Mod. on performance.

\section{Applying Behaviour Modification}

The major benefits of behaviour modification is that it encourages supervisors/managers to analyze employee behaviour, explore why it occurs and how often and identify specific consequences that will help change it, when they are applied systematically. Application of this process often encourages effective supervisors/managers to devote more time to monitoring strategy because they tend to be widely desired and therefore are strong reinforcements. Thus, behaviour modification allows more scientific analysis because it focuses on specific external consequences rather than intangible interval human needs. It is not easy to apply. In order to apply it, it is necessary to identify behavioural events that are to be modified/shaped to be productive and supportive to organizational goal attainment and then to determine what stimuli lead to them and how they are presently being reinforced. Based upon the facts uncovered by studying the work situation, an intervention strategy can be developed to encourage or discourage the behaviours considering the following guidelines.

\section{Guidelines For Applying Behaviour Modification In Organisation}

1. Identify exact behaviour to be modified.

2. Apply positive reinforcements as far as possible.

3. Apply punishment only in unusual circumstances/cases and for specific behaviour.

4. Ignore minor undesirable behaviour to allow its extinction.

5. Use shaping procedures (Reinforcements Schedules) to develop correct complex behaviour.

6. Minimize the time between the correct response and reinforcement.

7. Apply variable ratio reinforcement schedules where possible.

8. Provide reinforcement relatively frequently. 
If specific behaviour is identified and desirable reinforcements are properly applied, behaviour modification can lead to substantial improvements in specific areas such as absenteeism, tardiness and errors rates.

\section{Experiences with the Application of OB Mod}

Researchers and studies in increasing number have been carried out to evaluate the effectiveness of O.B. Mod applied in manufacturing, non-profit and service oriented organizations. The major findings of such studies are listed below:

\section{Employee Productivity}

Most of the organizations use behaviour modification techniques to improve employee productivity. A considerable number of research studies clearly indicate that employee productivity or task completion is positively affected by.

\section{Absenteeism and Tardiness}

Absenteeism and tardiness is another major area where behaviour modification is applied. Studies revealed that some combination of rewards (for example small monetary bonuses or lottery incentive systems) for attendance or promptness and/or punishers absenteeism or tardiness. They found very positive results. As those studies reported that an 18 to 50 percent reduction in the absenteeism rate and a 90 percent reduction in the frequency of tardiness. One study found a positive casual impact that an O.B. Mod. program had on the attendance of employee in a bank.

\section{Safety and Accident Preventation}

Most of the manufacturing firms and others in which dangerious equipments are used, are very concerned about safety and interested in decreasing accidents. Application of reinforcements have led to reduction of identifiable safety hazards and increasing safe behaviours among employees. A review of articles indicate the considerable success of behaviour modification techniques in the area of safety and accidents presentation. Some actual company examples are Boston Gas where employees without accidents are eligible for lottery drawings, Virginia Electric and Power Co, where employees can win from $\$ 50$ to 1000 for safety work habits. Southern New England Tele-communication which gives gift coupons to employee without accidents. So also, Turner corporation - a Newyork based engineering and construction firm where employee can earn company stock if they meet safety goals. All these companies report improved accident rate. 


\section{Sales Performance}

Sales managers and trainers have traditionally relied on internal motivation techniques to get their sales people to improve their sales performances. For example- one behaviour consultant suggested a company to give its sales personnel a typical high powered multimedia training program which teaches them effective selling skills. However, when the enthusiastic trainees finished the program and actually tried the things presented to them in the program, they receive little feedback or reinforcements. Within a few weeks, the enthusiasm began to decrease significantly because the sales people who acquired effective selling skills during their training environment did not get support in their job environment to use those skills. The effective application of O.B. Mod techniques have been found in improving selling behaviours such as customer's approach, suggestive statements and closing statements are identified, measured, analyzed, intervened and evaluated would be an alternative to motivate skill teaching approach. A recent comprehensive review of the behavioural approach to sales in restaurants, retail stores, wholesale companies and telephone operation found noteworthy success. By using a combination of antecedent and consequence intervention strategies, dramatic improvements were noticed in areas of wine and dessert sales, customer transactions, customer assistance, sales forecasting, sales call frequency, sales of telephone services and airline reservation. The successful application of O.B. Mod to the selling, absent from the work station and idle time behaviours of clerks in a large retail store is reported.

\section{Limitations}

Behaviour modification has been criticized on several grounds, its philosophy, methods and practicality. Because of the strong power of desired consequences, behaviour modification may effectively force people to change their behaviour. In this way, it manipulates people and is inconsistent with humanistic assumptions that people want to be autonomous and self actualizing. Some critics do fear that behaviour modification gives too much power to the supervisors/managers and they put the question: who will control the controller?

Likewise, some critics are of the opinion that behaviour modification insults people intelligence. People could be treated like rats in a training box. But infact, people are intelligent, thinking, self-directed and self-controlled individuals who are capable of making their own judgements and choices and motivating themselves. Another limitation is that behavioural modification has limited applicability to complex jobs. For example- it is difficult to identify critical behaviours in the jobs of company lawyer, flight attendants 
and chief executive officers and reinforce them. This challenge may become more difficult as the economy becomes more and more service based.

Behavioural modification has basically overlooked people's cognitive (judgement and choice) skills as active participants in the performance process. It has also minimally considered the influence of antecedents cues on their behaviour. These limitations have led to the emergence of social learning theory which is a more recent adaption of the behaviour modification process.

Inspites of the above limitations as indicated by critics, organizations are increasingly applying behavour modification as an efficacious tool of shaping/molding individual behaviour productive and supportive in the attainment of organizational goal.

\section{References}

Arnold H.J. \& Daniel C. Feldman (1988). Organizational Behaviour, Mc- Graw Hill International Editions Robbins, Stephen P. (1999). Organizational Behaviour, Prentice Hall of India, $8^{\text {th }}$ edition John W. Nelostron \& Keith Davis (1996). Organizational Behaviour,, Tata McGraw Hill Editions

Mitchell, Terence R. \& Larson, James R. People In organization: An introduction to organizational Behaviour, New Delhi, Mc-Graw Hill International Editions, $3^{\text {rd }}$ Edition

Luthans, Fred (1984). Organizational Behaviour, Mc-GrawHill International Editions- $5^{\text {th }}$ Edition Kelly, Joe (1987). Organizational Behaviour, Surjeet Publication India.

Porter, Layman W., Edward E Lawter III, Stackman J Richard. Behaviour in organization, Mc-Graw-Hill International Student Edition

Dwivedi, R S (1997). Human Relation \& Organizational Behaviour, Mc Millon India Ltd. Fourth Edition. Agrawal, Govinda Ram. Organizational Behavior in Nepal, M K Publishers \& Distributors KTM Nepal. 